\title{
O princípio da solidariedade no enfrentamento da COVID-19 no Brasil
}

\author{
The principle of solidarity in facing COVID-19 in Brazil \\ El principio de solidaridad frente al COVID-19 en Brasil
}

Márcia Haydée Porto de Carvalho ${ }^{1}$

Márcia Lúcia Lopes de Miranda²

\section{Resumo}

Objetivo: analisar o princípio da solidariedade como vetor interpretativo para as políticas públicas emergenciais e outras ações de enfrentamento da pandemia COVID-19. Metodologia: utilizou-se o método dedutivo como abordagem; o método descritivoexploratório como procedimento; e como técnicas de pesquisa a bibliográfica e documental. Resultados: verificou-se que, apesar do avanço das políticas públicas de saúde, notadamente por meio do Sistema Único de Saúde (SUS), o princípio da solidariedade ainda está sendo desconsiderado no enfrentamento da pandemia no Brasil, como se vê, por exemplo, pela estocagem de testes RT-qPCR prestes a vencer e subutilização do orçamento destinado à pandemia. Embora já demonstrado que medidas orientadas por esse princípio salvam vidas, como revelam experiências exitosas de outros países, sendo um instrumento eficaz e pouco oneroso, muito há a avançar na aplicação de tal princípio no Brasil. Conclusão: inspirados pelo princípio da solidariedade, os governos federal, estaduais e municipais, e demais poderes, devem conjugar esforços para oferecer políticas públicas e outras ações adequadas e eficazes ao combate da COVID-19 no Brasil.

\section{Palavras-chave}

Pandemia COVID-19. Políticas públicas de saúde. Princípio da solidariedade.

\begin{abstract}
Objective: analyzing the principle of solidarity as an interpretive vector for urgent public policies and other actions to combat the COVID-19 pandemic. Methodology: the deductive approach, the descriptive-exploratory method of procedure and the bibliographic and documentary research techniques were used. Results: it was found that, despite the advancement of public health policies, notably through SUS (Unified Health System), the principle of solidarity is still being disregarded in the face of the pandemic in Brazil, as seen, for example, by the storage of RT-qPCR tests (about to expire) and underutilization of the budget for the pandemic. Thus, although it has already been demonstrated that measures informed by this principle save lives, as revealed by successful experiences in other countries, being, therefore, an effective and inexpensive instrument, much remains to be done in the application of this principle in Brazil. Conclusion: inspired by the principle of solidarity, the federal, state and municipal governments, and other powers, must combine efforts to offer public policies and other appropriate and effective actions to combat COVID19 in Brazil.

\footnotetext{
${ }^{1}$ Doutora em Direito do Estado, Pontifícia Universidade Católica de São Paulo, São Paulo, SP, Brasil; professora associada I, Departamento de Direito, Universidade Federal do Maranhão, São Luís, MA, Brasil. https://orcid.org/0000-0002-07834302. E-mail: marciahaydee@uol.com.br

${ }_{2}$ Mestranda em Direito e Instituições do Sistema de Justiça, Universidade Federal do Maranhão, São Luís, MA, Brasil; servidora pública, Tribunal Regional do Trabalho da 16ª Região, São Luís, MA, Brasil. https://orcid.org/0000-0003-48175523. E-mail: malumiranda@uol.com.br
} 


\section{Keywords}

COVID-19 pandemic. Public health policies. Principle of solidarity.

\section{Resumen}

Objetivo: analizar el principio de solidaridad como vector interpretativo de políticas públicas de emergencia y otras acciones para combatir la pandemia COVID-19. Metodología: se utilizó el enfoque deductivo, el método de procedimiento descriptivo-exploratorio y las técnicas de investigación bibliográfica y documental. Resultados: se encontró que, a pesar del avance de las políticas públicas de salud, en particular a través del SUS (Sistema Único de Salud), el principio de solidaridad sigue siendo desatendido frente a la pandemia en Brasil, como lo ha visto, por ejemplo, el almacenamiento de pruebas RT-qPCR (a punto de expirar) y subutilización del presupuesto para la pandemia. Así, si bien ya se ha demostrado que las medidas fundamentadas en este principio salvan vidas, como lo revelan experiencias exitosas en otros países, siendo, por tanto, un instrumento eficaz y económico, queda mucho por hacer en la aplicación de este principio en Brasil. Conclusión: inspirados en el principio de solidaridad, los gobiernos federal, estatal y municipal, y otros poderes, deben aunar esfuerzos para ofrecer políticas públicas y otras acciones adecuadas y efectivas para combatir el COVID-19 en Brasil.

\section{Palabras clave}

Pandemia de COVID-19. Políticas de salud pública. Principio de solidaridad.

\section{Introdução}

O presente estudo baseia-se no exame do princípio universal da solidariedade, inserido expressamente no texto constitucional brasileiro como objetivo fundamental da República Federativa do Brasil, no art. $3^{\circ}$ da Constituição Federal de 1988 (CRFB).

Parte-se de uma abordagem inicial sobre a universalidade do princípio e suas nuances gerais, bem como a previsão na CRFB e sua aplicabilidade em momentos excepcionais de grave crise, como a que ora se atravessa. Serve, assim, de norte ou vetor interpretativo para as ações do Executivo - nas esferas federal, estadual e municipal de governo -, e dos outros poderes, no enfrentamento da crise sanitária da COVID-19 no Brasil.

Busca-se ainda demonstrar os benefícios das políticas públicas solidárias, a exemplo de diversas ações orientadas por esse princípio no plano internacional, com a conjugação de esforços governamentais para superação dos problemas decorrentes da pandemia, nos âmbitos sanitário, político e econômico, afastando com isso eventuais divergências políticas e outros entraves administrativos, pela máxima da solidariedade, tendo como centro a defesa da vida humana. Analisa-se igualmente a influência do princípio da solidariedade sobre as ações dos outros poderes, a exemplo da inspiração que naturalmente exerce sobre o Judiciário, nas matérias que acabam sendo judicializadas nesse tempo pandêmico. 
A aplicação do referido princípio destina-se, sobretudo, à melhoria das políticas públicas de saúde no Brasil, como revela a própria essência do Sistema Único de Saúde (SUS), visando uma atuação unificada de enfrentamento à pandemia, diferentemente de ações governamentais isoladas e muitas vezes conflitivas, sem a eficaz conjugação de esforços, o que acaba refletindo negativamente no próprio controle da doença, gerando impacto social ainda maior.

Diante de tal cenário, pergunta-se: em que medida está sendo desconsiderado o objetivo fundamental da solidariedade no que se refere ao enfrentamento do novo coronavírus no Brasil?

Na esteira de Robert Alexy (1), acerca do princípio como mandamento de otimização, o presente trabalho visa dar ênfase ao princípio da solidariedade como luz para atuação do Executivo e demais poderes, de forma a adotar-se políticas públicas ou ações harmônicas voltadas à garantia efetiva de direitos fundamentais no Brasil, superando assim os mais diversos problemas decorrentes da crise sanitária mundial.

\section{Metodologia}

Para o presente estudo, adotou-se como abordagem o método dedutivo, tomando-se como hipótese o princípio da solidariedade, constitucionalmente previsto, deduzindo-se dele a sua importância para o enfrentamento da COVID-19 no Brasil.

Quanto ao procedimento, utilizou-se o método descritivo-exploratório, partindo do estudo de caso, o que abrangeu o aprofundamento do tema da solidariedade, desde a sua base principiológica universal e a previsão constitucional brasileira, assim como das políticas públicas de saúde, do SUS e a legislação correlata. Também foram estudados os novos caminhos que se propõem com a aplicação do princípio da solidariedade no combate à pandemia COVID-19 no Brasil a partir das experiências internas, bem como das experiências estrangeiras, à luz do citado princípio.

Como pesquisa exploratória, utilizou-se o levantamento bibliográfico, incluindo livros jurídicos, artigos científicos e informativo jurisprudencial tomado por amostragem, além de publicações na internet que revelassem a importância da aplicação do princípio da solidariedade no estado pandêmico atual, tanto em face da escassez de literatura específica sobre o tema, como pelo avanço das tecnologias digitais durante a própria pandemia, que permitiu fácil acesso e ampla divulgação de publicações sobre a crise sanitária mundial. 
Destaca-se ainda não ter havido recorte temporal, nem tampouco critério específico de inclusão e exclusão do material bibliográfico e documental, exceto pela maior aproximação com o tema da solidariedade, políticas públicas de saúde e outras ações de combate à pandemia da COVID-19, no Brasil e no mundo.

Também no que se refere à análise das experiências estrangeiras exitosas, foram escolhidas matérias publicadas na internet, cujo conteúdo se mostrou mais próximo à identificação do princípio da solidariedade em países que tiveram êxito no combate à COVID19.

\section{O princípio da solidariedade}

A solidariedade como princípio universal

A ideia de solidariedade surgiu ainda na Antiguidade clássica, quando já se cogitava o homem como um animal cívico, mais sociável do que qualquer outro, que se agregava a outros seres humanos para tornar a vida menos custosa e sacrificante (2). Foi a partir dos estudos filosóficos de Aristóteles que se construiu, pela primeira vez na civilização humana, a ideia de solidariedade.

A solidariedade possui grande expressão no seu antepassado, vinculado a duas vertentes intelectuais: o estoicismo e o cristianismo primitivo, nos quais o homem associavase pelo amor fraterno (filhos do mesmo pai), havendo, pois, um dever de cooperação, decorrente da própria coexistência, que implicava em uma obrigação moral para atender interesses comuns (ideia de reciprocidade). Por sua vez, os juristas romanos também usavam a palavra para designar o laço que unia todos os devedores, a chamada responsabilidade in solidum (responsabilidade solidária) (3). No momento de sua origem, a solidariedade era desprovida de normatividade e se traduzia mediante a expressão dos valores humanos, sendo que, na maioria das vezes, a solidariedade era equiparada à fraternidade (4).

Superado o viés individualista, próprio do Estado Liberal, surge a concepção do ser humano como detentor de direitos sociais e, por consequência, a necessidade de o bemestar social ser protegido, podendo sobrepor-se, inclusive, aos interesses privados. Em vista disso, passa a ser exigida a construção de uma sociedade pautada no ideal de solidariedade, a ser exercido tanto pelo Estado, quanto pelos indivíduos (5).

Pelas barbáries cometidas durante o período da Segunda Guerra Mundial, surgiu a necessidade de se reconstruírem os direitos humanos, o que foi materializado por meio da 
Declaração Universal dos Direitos Humanos, de 1948, um marco do Direito Contemporâneo, cujas premissas se assentam na proteção da dignidade humana e no ideal de solidariedade.

A Declaração Universal de 1948 permitiu uma reaproximação do Direito e da ética, atribuindo status normativo aos princípios e iniciando um novo sistema pautado, principalmente, na realização do princípio da dignidade humana enquanto valor fonte de todo o sistema jurídico, daí surgindo a solidariedade para potencializar e concretizar esse princípio-matriz do ordenamento (6).

Distanciando-se do individualismo característico do fim do século XIX e início do século XX, aflora o princípio da solidariedade, trazendo "[...] significado ao próximo, correlacionando-se, pois, a um modo de despertar a intencionalidade humana em reconhecer a existência do outro, porque conduz o comportamento à consciência perceptiva do seu ambiente social" (7). A solidariedade passa a ser vista, então, com maior amplitude, e não apenas como caridade ou filantropia (fim do séc. XIX), dentro de uma nova perspectiva de construção de políticas sociais concretas. Trata-se, pois, de "[...] um fio condutor indispensável à construção e à conceitualização das políticas sociais" (3). Não se trata de imposição à liberdade individual, mas de um valor voltado à concretização da dignidade da pessoa humana, devendo para tanto permear todas as ações individuais e concentrar-se na coletividade, buscando a harmonia e a cooperação entre as pessoas. Assim, o princípio da solidariedade leva cada indivíduo a colocar-se no lugar do outro, o que gera um tratamento mais harmonioso e benéfico aos envolvidos no conflito.

Em vista da amplitude do conceito de solidariedade, é possível concebê-lo sob três enfoques: valor moral, valor ético e valor jurídico. Sob o aspecto moral, a solidariedade deve ser entendida como "[...] generosidade, bondade e compaixão, intimamente ligada à ideia de caridade proveniente do cristianismo". Como valor ético, liga-se à solidariedade filosófica, ou seja, a partir da cooperação com o outro, dentro de uma perspectiva de alteridade. Enquanto valor jurídico, liga as pessoas sob uma perspectiva do bem comum (partes de um todo social) (8).

No tocante às gerações de direitos fundamentais e pautado no escólio de Bonavides e Schafer, recorda-nos o Ministro Reynaldo Soares da Fonseca (9), em seu artigo Direitos de fraternidade na teoria das gerações de direitos fundamentais, que a fraternidade, assim como a solidariedade, estão inseridas nos direitos fundamentais de terceira geração, com titularidade dispersa (difusa ou coletiva), abrangendo os direitos ao desenvolvimento, à paz, 
ao meio ambiente, à propriedade sobre o patrimônio comum da humanidade e de comunicação.

Segundo Philippe Perrenoud (10), a solidariedade não é inerente ao indivíduo em si:

Ninguém pode ser solidário sozinho. A solidariedade é um fato social. Por isso, falarei dela como sociólogo. Naturalmente, assim como a todas as pessoas de boa vontade, a solidariedade parece-me mais simpática, mais humana, mais positiva que seu contrário. Porém, se todos estivéssemos de acordo sobre esse ponto, todos seriam solidários com todos, e não haveria nem guerra, nem miséria, nem desigualdades, nem dominações, nem segregações, nem violências, nem exclusões. (10)

A solidariedade, em seu aspecto universal, passa a ser vista sob uma perspectiva mais ampla, de construção de políticas sociais concretas, dentre as quais devem estar inseridas as políticas públicas de saúde.

\section{Previsão constitucional brasileira}

O valor oriundo do princípio da solidariedade foi verdadeiramente considerado no ordenamento jurídico brasileiro somente a partir da promulgação da Constituição Federal de 1988, que passa a consagrá-lo como grande premissa para potencializar e concretizar o princípio-matriz da dignidade da pessoa humana (6).

A CRFB bem expressa, portanto, a mudança de paradigma resultante da Declaração Universal dos Direitos Humanos, em face das inúmeras violações perpetradas no período da Segunda Guerra Mundial, daí emergindo a força normativa dos princípios por ela consagrados, especialmente o da dignidade da pessoa humana, pela efetiva preocupação com o ser humano, cujos direitos foram tão aviltados (11).

A solidariedade tem previsão no Título I da CRFB, relativo aos princípios fundamentais, especificamente no art. $3^{\circ}$, dentre os objetivos fundamentais da República Federativa do Brasil, como adiante se vê:

Art. $3^{\circ}$ Constituem objetivos fundamentais da República Federativa do Brasil: I - construir uma sociedade livre, justa e solidária;

II - garantir o desenvolvimento nacional;

III - erradicar a pobreza e a marginalização e reduzir as desigualdades sociais e regionais;

IV - promover o bem de todos, sem preconceitos de origem, raça, sexo, cor, idade e quaisquer outras formas de discriminação. (12, grifo das autoras)

Segundo Cardoso (2), a aplicação da solidariedade dá-se em dois planos distintos: no plano horizontal - vínculo entre os seres humanos - e no plano vertical. No plano 
horizontal, a solidariedade é muito mais do que fraternidade e caridade. Diz respeito ao agir humano ou às ações cotidianas das pessoas, voltadas ao bem-estar coletivo. É colocar-se no lugar do outro. Já no plano vertical, a solidariedade, por estar prevista na CRFB, funciona como um princípio informador do sistema jurídico que, visando estabelecer uma convivência harmoniosa entre os homens, espalha sua força perante todo o ordenamento jurídico. A força vinculante desse importante princípio exige uma atitude proativa por parte do Estado, ou seja, ele deve atuar na promoção social com o objetivo de garantir que esse processo de convivência equilibrada entre os cidadãos seja, de fato, concretizado (6).

À luz da teoria de Alexy (1), os princípios, que considera como direitos fundamentais ou bens constitucionalmente protegidos, são definidos como mandamentos de otimização, ou seja, são normas que podem ser realizadas em diferentes graus, na maior medida possível, segundo as possibilidades fáticas e jurídicas existentes. A Constituição ocupa posição central, na medida em que incorpora os direitos humanos e os transforma em direitos fundamentais, fazendo-os irradiar por todo o ordenamento e condicionar a sua compreensão. Considerando a força normativa da Constituição e a irradiação dos princípios e direitos fundamentais por todo o ordenamento jurídico, o princípio ou direito fundamental à solidariedade pode ser visto como um vetor de interpretação para todas as condutas que são efetivadas sob sua égide (13).

Todavia, não basta a simples previsão da solidariedade no ordenamento jurídico se a sua aplicação se faz ausente. Moraes (14) informa o que deve ser pensado quando se fala sobre a solidariedade:

[...] a expressa referência à solidariedade, feita pelo legislador constituinte, longe de representar um vago programa político ou algum tipo de retoricismo, estabelece um princípio jurídico inovador em nosso ordenamento, a ser levado em conta não só no momento da elaboração da legislação ordinária e na execução das políticas públicas, mas também nos momentos de interpretação-aplicação do Direito, por seus operadores e demais destinatários, isto é, pelos membros todos da sociedade. (14)

Para Casalli (15), a solidariedade, enquanto objetivo fundamental da República Federativa do Brasil, "[...] deve envolver toda a sociedade, abrindo espaços de diálogo e não sendo encarada como o simples fato de fazer caridade. A solidariedade é isto e muito mais, além desta ajuda ela constitui-se em elemento integrador de uma nação e facilitadora da democracia". 
Assim, a CRFB consagra o princípio da solidariedade como grande premissa para assegurar o respeito à dignidade humana (princípio-matriz), cujos efeitos irradiam positivamente ao integrar a nação e garantir o próprio exercício da democracia.

\section{A solidariedade e a crise pandêmica no Brasil}

\section{Um olhar para novos caminhos}

O quadro pandêmico avassalador, gerado pela COVID-19, possibilitou o resgate de temas essenciais como o princípio da solidariedade e da fraternidade, como pistas ou vetores para superação dos graves problemas que decorrem da crise sanitária.

É certo que se vive um desastre humanitário gerado por uma crise de saúde mundial sem precedentes, que afeta toda a humanidade, comprometendo-Ihe a própria subsistência, já que o emprego e renda foram diretamente atingidos.

Como bem pontuou o Ministro Reynaldo Soares da Fonseca, do Superior Tribunal de Justiça (STJ):

[...] vive-se um desastre humanitário, provocado por uma pandemia que tornou ou tornará todos os seres humanos mais pobres em termos materiais. O momento, ressaltou, exige uma reflexão sobre temas importantes como a integridade, a fraternidade e os caminhos do direito e da humanidade na sociedade democrática [...] o artigo $3^{\circ}$ da Constituição Federal é peremptório no sentido de assegurar a construção de uma sociedade fraterna na solução pacífica de conflitos [...] "Efetivamente, o caminho da solidariedade, o caminho daquilo que estamos propondo como um princípio esquecido para que seja reavivado - o princípio da fraternidade -, é o caminho do século XXI, especialmente depois da pandemia. Esperamos que todos consigamos ultrapassar essa fase e possamos voltar a discutir políticas públicas. (16)

Esse cenário nos conduz a um olhar diferenciado em busca de novos caminhos, por meio dos quais se construa um futuro pautado em ações solidárias, cujo centro seja o homem em sua universalidade, de modo a garantir-lhe sobrevivência digna, independentemente de origem, raça, credo ou condição social.

No combate à pandemia, o espírito solidário foi se tornando força motriz, disseminando-se entre os mais diversos segmentos e sob variadas formas, a exemplo das ações voluntárias de apoio a pessoas em estado de vulnerabilidade social, aos psicologicamente fragilizados e aos idosos.

Segundo Cris Fernández Andrada, a principal motivação das iniciativas solidárias está relacionada ao reconhecimento da dor do outro: "[s]eres humanos são seres coletivos que se identificam com a mesma condição diante de crises agudas que ameaçam nossa 


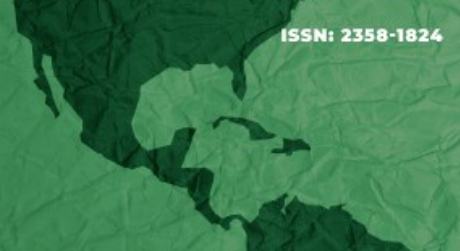

existência" (17). Assim, um novo olhar há de ser lançado em direção àquele que sofre ou agoniza: "[t]orna-se necessário, então, a criação de novas formas de solidariedade, com os homens se reconhecendo membros de uma mesma sociedade, olhando uns para os outros" (18).

Em relação à solidariedade como princípio fundante da seguridade social constitucionalmente prevista, deve-se destacar:

O princípio da solidariedade influencia todo Direito da Seguridade Social, principalmente quanto à Previdência Social e à Assistência Social, na manutenção da dignidade da pessoa humana e no respeito dos direitos sociais, através de ações promotoras da justiça social e garantidoras da proteção aos indivíduos que se encontrem em situações de necessidade decorrentes de contingências sociais. (19)

O horizonte que se avizinha, portanto, é o de mudanças substanciais, especialmente no campo valorativo que gira em torno do ser humano, onde deverão ser consagrados princípios universais como o da solidariedade e da fraternidade, como vetores de políticas públicas e das ações da sociedade como um todo.

Pelas próprias circunstâncias da crise sanitária e suas implicações, e em um contexto de alta judicialização, faz-se premente uma mudança de paradigma voltado à construção de uma sociedade solidária e fraterna, com convergência de ações, onde se priorize a solução pacífica dos conflitos. Essencial que se construam novas trilhas ou pontes para uma atuação solidária de todos, individual e coletivamente, em um verdadeiro pacto de solidariedade, no sentido de encontrar-se, pela união de forças, caminhos de superação.

\section{Direito à saúde - políticas públicas - SUS (Sistema Único de Saúde)}

O direito à saúde, enquanto direito social, integra o rol de direitos fundamentais na CRFB, estando previsto no art. $6^{\circ}$ (Título II - Dos Direitos e Garantias Fundamentais; Capítulo II - Dos Direitos Sociais), assim como no art. 196 (Título VIII - Da Ordem Social; Capítulo II - Da Seguridade Social) (12).

A Organização Mundial da Saúde (OMS) define a saúde, no preâmbulo de sua Constituição, como o "[...] estado completo de bem-estar físico, mental e social e não meramente a ausência de doença ou enfermidade" (20).

Tal conceituação pela OMS revela sua amplitude e "[...] realça o caráter complexo e multifacetado da saúde, que não pode ser compreendida apenas como ausência de doenças", nem tampouco na dimensão puramente individual, "[...] sendo a um só tempo 


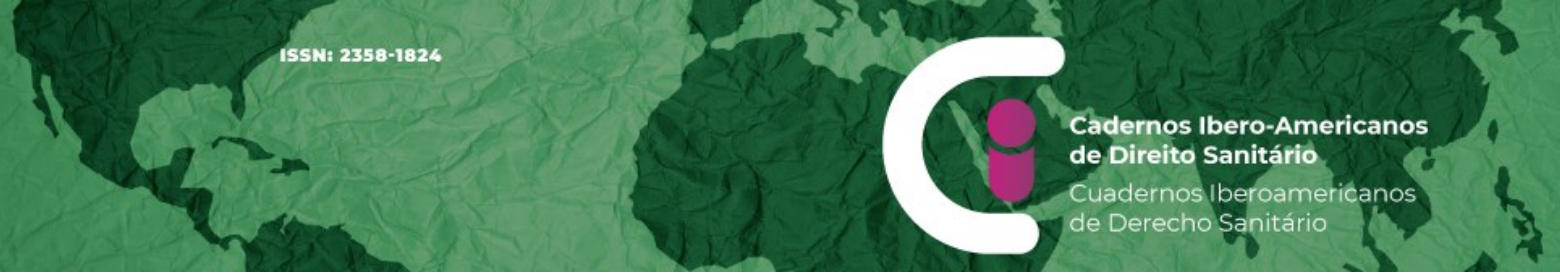

direito individual e social". O direito à saúde é também um "[...] bem coletivo, exigindo a participação da sociedade e do Estado na sua promoção", conforme bem destacado na Constituição da Organização Mundial da Saúde (21).

A Constituição da OMS figura como marco normativo importante acerca do conceito de saúde, desligando-o da visão anterior, meramente individual, e reconhecendo o seu duplo caráter individual e social. Correlaciona a saúde das pessoas ao desenvolvimento socioeconômico, dentro de estratégias amplas de promoção da saúde, preceito esse também albergado pela CRFB.

É direito do cidadão o acesso à saúde, assim como é dever do Estado prestá-la:

[...] é que existe a necessidade de criação de políticas públicas para acesso dos cidadãos às ações e serviços de saúde e, como forma de atingir sua promoção, proteção e recuperação. Isto ocorre, pois é através da interferência das políticas públicas de saúde, por exemplo, que se garante a qualidade de vida, a dignidade e, dessa forma, uma autêntica cidadania [...]. (22)

Enquanto elemento de transformação social, as políticas públicas são:

[...] conjuntos de programas, ações e decisões tomadas pelos governos nacional, estadual ou municipal que afetam a todos os cidadãos, de todas as escolaridades, independente de sexo, cor, religião ou classe social. A política pública deve ser construída a partir da participação direta ou indireta da sociedade civil, visando assegurar um direito a determinado serviço, ação ou programa. No Brasil, o direito à saúde é viabilizado por meio do Sistema Único de Saúde (SUS) que deverá ser universal, integral e gratuito. (23)

O SUS é a principal política pública de saúde brasileira, cujos princípios foram sendo insculpidos ao longo de programas iniciais ou marcos históricos importantes, a exemplo da VIII Conferência Nacional de Saúde, realizada em 1986, logo após o fim da ditadura militar, impulsionada pelo processo de reforma sanitária, ou movimento sanitarista, onde foram discutidas as políticas de saúde como questão coletiva (24).

O SUS, enquanto sistema nacionalmente unificado, foi instituído a partir da CRFB, abrangendo as ações e serviços públicos de saúde integrantes de uma rede regionalizada e hierarquizada, que constituem um sistema único, organizado com base nas seguintes diretrizes, estabelecidas no art. 198 da CRFB: I - descentralização, com direção única em cada esfera de governo; II - atendimento integral, com prioridade para as atividades preventivas, sem prejuízo dos serviços assistenciais; III - participação da comunidade (12). 


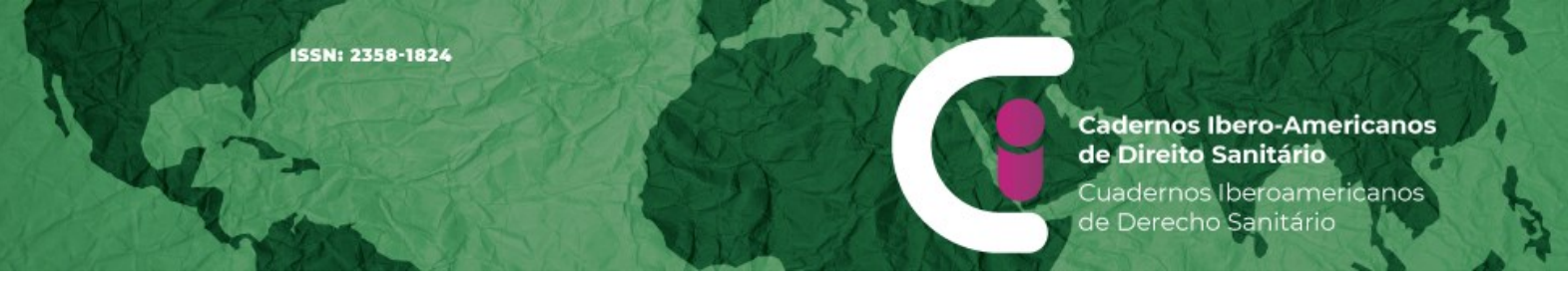

Após a constitucionalização do sistema único de saúde nacional, prevista no art. 196 da CRFB, foi editada a legislação específica para regulamentar a matéria, a chamada Lei Orgânica da Saúde (Lei n 8.080/90), com previsão dos princípios norteadores no art. $7^{\circ}$ da referida Lei (25).

Ao longo dos anos, desde a implementação do SUS em 1990, muitas iniciativas foram sendo tomadas para a descentralização e municipalização das ações de saúde, cujo processo evidenciou as diferenças de realidade social, política e administrativa de cada localidade, tornando mais complexa a rede de serviços.

A responsabilidade pela gestão do SUS foi inicialmente atribuída aos três níveis de governo ( $1^{\mathrm{a}}$ etapa), até que em 2006 foi instituído o Pacto pela Saúde ( $2^{\mathrm{a}}$ etapa), enquanto conjunto de reformas nas relações institucionais e fortalecimento da gestão compartilhada do SUS, introduzindo mudanças nas relações entre os entes federados, inclusive nos mecanismos de financiamento, num grande esforço de atualização e aprimoramento do sistema.

Para adesão ao Pacto, os gestores assinam um termo de compromisso, com eixos prioritários e metas a serem atingidas, onde são firmados compromissos em três dimensões: Pacto pela Vida, Pacto em Defesa do SUS e Pacto de Gestão.

A esse respeito, cumpre destacar:

As mudanças se dão com a intenção de fortalecer os processos de cooperação e solidariedade entre entes federados (União, estados e municípios) e reafirma os princípios constitucionais do SUS. As inovações estão presentes na ênfase dada às pactuações regionais celebradas e gerenciadas nos colegiados regionais de saúde, na medida em que se toma a regionalização como eixo estruturante de organização das redes de atenção à saúde que possibilite atenção integral ao usuário [...]. (26, grifo das autoras)

O princípio da solidariedade está, portanto, perfeitamente delineado, assim como o ideal de cooperação, na essência do Pacto pela Saúde, em suas três dimensões, nas quais são priorizadas ações conjuntas pelos gestores pactuantes, em defesa da vida e do próprio SUS e de sua gestão.

Ressalte-se, ainda, que a solidariedade aqui tratada:

[...] enquanto norte constitucional e de organização do Estado e de suas políticas públicas, refere-se a um sentido de cooperação mútua entre pessoas ou entes; identidade; interdependência de sentimentos e ideias [...] Distinguese, portanto, do conceito jurídico de obrigações solidárias, disposto no artigo 264 do Código Civil Brasileiro, que se refere à concorrência de mais de um 
devedor ou obrigado à determinada prestação, que não pode (e não deve) ser utilizado no âmbito da saúde, sob pena da total desorganização do SUS [...] (27).

A solidariedade, por sua vez, não deve ser vista no sentido da imposição das mesmas responsabilidades de garantia do direito à saúde em relação a todos os entes federativos, indistintamente, sob pena de eventual condenação judicial para atender um único paciente acabar comprometendo o orçamento de uma coletividade inteira.

As políticas públicas de saúde ensejam, portanto, rico debate, especialmente quanto à pandemia da COVID-19 no Brasil, cuja gravidade requer uma convergência de ações ou programas entre todos os entes federativos, com bases alicerçadas no próprio SUS, pautado, na sua essência, na efetiva participação de todos os entes da federação, ou federalismo cooperativo, conforme a CRFB.

Apesar do quadro desafiador, não há como negar o êxito do SUS no combate à crise pandêmica, em que restou provada a solidez do sistema ao serem mantidas as ações e programas de saúde. Os problemas impostos pela própria dimensão continental do Brasil, a exemplo do difícil acesso e distribuição de insumos hospitalares e medicamentos às regiões mais distantes, foram enfrentados seriamente, servindo de referência mundial como sistema público de saúde e de acesso universal a todos os brasileiros.

\section{Solidariedade e pacto federativo}

Apesar dos benefícios decorrentes de uma ação solidária no combate à pandemia, experimentou-se no Brasil significativo confronto em diversas questões de enfrentamento à crise sanitária, o que trouxe sérios prejuízos e entraves à resolução de tais problemas.

Diferentemente do que se exigiria para o momento de crise, houve grande divergência entre governantes e gestores públicos desde o início da decretação do estado nacional de emergência, sobretudo em relação às medidas de isolamento social, fechamento do comércio e definição de protocolos médicos de combate à doença, o que revelou a existência de tensões no pacto federativo.

Muito embora a Constituição Federal estabeleça rol de competências administrativas exclusivas (art. 21) ou competências privativas da União (art. 22), há previsão expressa acerca das competências comuns em matéria de saúde, mas também de políticas educacionais, meio-ambiente, cultura, indicando o caminho do federalismo cooperativo como sendo o centro do modelo constitucional adotado. O art. 24 igualmente dispõe sobre 
as competências concorrentes, o que denota a perspectiva de atuação conjunta entre União e Estados, em assuntos de grande relevância, cabendo ao ente federal fixar as regras gerais e aos entes estaduais, as regras suplementares.

Em relação às políticas públicas de combate à pandemia, destaca-se o inciso II do art. 23, quanto à competência comum para cuidar da saúde; e o inciso XII do artigo 24, que inclui a proteção e a defesa da saúde no âmbito da competência concorrente, sem descuidarse ainda da previsão do art. 30, I e II, também da CRFB, relativo às competências locais e suplementares dos municípios.

Vê-se que a previsão constitucional em matéria de saúde impõe uma ação coordenada entre União, Estados, DF e Municípios para construírem soluções conjuntas, de modo a garantir a efetividade das políticas públicas essenciais à superação da crise, no que se revela essencial a aplicação do princípio da solidariedade.

Quanto ao federalismo cooperativo, vale citar a Ação Direta de Inconstitucionalidade proposta pela Confederação Nacional de Saúde (CNS) - ADI n 6362 - contra a validade de dispositivos da Lei $\mathrm{n}^{\circ}$ 13.979/2020 (28), que permitem aos gestores locais de saúde adotarem a requisição de bens e serviços sem o controle da União (29).

A ação foi julgada improcedente, em 02/09/2020, tendo o STF decidido que todas as requisições realizadas por estados, municípios e Distrito Federal, no combate ao coronavírus, não dependem de prévia análise nem de autorização do Ministério da Saúde, mas devem se fundamentar em evidências científicas e serem devidamente motivadas (29).

O relator reforçou que não deve haver primazia no poder de requisição, mas uma cooperação necessária entre os entes e uma responsabilidade comum. O ministro Lewandowski ressaltou que o federalismo fortalece a democracia, porque permite o acesso do cidadão ao governante mais próximo, no caso, os municípios, a quem cabe agir dentro de sua competência derivada prevista na Constituição Federal (29).

$\mathrm{Na}$ visão de Marco Aurélio Marrafon (30), "[...] são indispensáveis atitudes não predatórias entre os entes federados, isto é, as autoridades devem evitar confrontos, conciliar as diferenças e reforçar os pontos de convergência".

Prossegue o referido autor, destacando:

[...] se o Poder Executivo Federal ou mesmo o presidente da República tomar decisões manifestamente incompatíveis com as orientações científicas e as políticas internacionalmente referendadas, é possível que os estadosmembros, Distrito Federal e municípios exerçam o direito de resistência federativa. Ou seja, os entes subnacionais podem utilizar suas prerrogativas 
de auto-organização, autogoverno, autoadministração e autolegislação para implementar as ações necessárias. Ao mesmo tempo, devem buscar todas as possibilidades de atuação conjunta com órgãos federais de índole mais técnica, como as agências reguladoras, avançar no diálogo político com o Congresso Nacional e, em última ratio, recorrer ao Poder Judiciário (...). Cumpre aos agentes políticos deixarem de lado questões menores e populistas e exercerem com espírito coletivo e força de estadista o mandato a eles confiado pelo povo brasileiro. (30)

Nesse sentido, apesar da atuação destacada do SUS no combate à COVID-19, inúmeros prejuízos decorreram da não aplicação do princípio da solidariedade: ações isoladas e disputas políticas inapropriadas, com séria discordância nas medidas tomadas durante a pandemia, o que implicou em desgastes desnecessários, com a judicialização de conflitos e retardamento de ações emergenciais de combate à proliferação do vírus.

Mais recentemente, em novembro de 2020, já na iminência de uma segunda onda de contaminação, explodiram denúncias no noticiário nacional acerca da estocagem ou represamento de testes RT-qPCR em armazém do governo federal em Guarulhos/SP, prestes a vencer em dezembro de 2020 ou início de 2021, sem a devida distribuição entre os diversos estados (31). Trata-se de claro negativismo ao princípio da solidariedade, uma vez que, muito embora indispensável a realização de testagem em massa da população para o próprio controle epidemiológico, deixou-se de fazê-lo em muitas localidades por falta de oportuna distribuição dos kits represados.

Do mesmo modo, ainda como típica hipótese de inaplicabilidade do princípio, viu-se também noticiada a subutilização do orçamento da pandemia destinado à contratação de profissionais de saúde, reestruturação hospitalar, compra de testes de COVID-19, fomento à agricultura familiar, dentre outros fins (32), chegando-se à triste marca de apenas 4,6\% do orçamento efetivamente utilizado para mitigar os efeitos da crise sanitária, conforme relatório da Câmara dos Deputados, com dados até 20 de novembro de 2020. Evidente, portanto, em tais casos, a inaplicabilidade ou mitigação do princípio da solidariedade, em claro prejuízo à eficácia do combate pandêmico.

Por outro lado, se as ações governamentais estivessem pautadas no princípio da solidariedade, teria sido evitado um grande dispêndio de tempo e dinheiro, por meio da conjugação de esforços para uma atuação nacional convergente - como a abertura de novos leitos de UTI e distribuição de respiradores -, sem espaço para conflitos ou disputas políticas inoportunas. Países que assim agiram tiveram maior êxito e eficácia nas medidas adotadas, 
com o achatamento precoce das curvas de contágio e maior segurança no retorno das diversas atividades.

\section{Aplicação do princípio em decisões judiciais}

O fenômeno da judicialização da saúde tem sido tema recorrente no Brasil ao longo dos anos, especialmente durante o período pandêmico (COVID-19), quando diversas matérias foram submetidas à apreciação do Judiciário em decorrência da crise sanitária, em variados âmbitos.

Para fins de identificação do princípio da solidariedade em tais decisões, estabeleceuse uma análise, por amostragem, de algumas decisões proferidas pelo STF (Supremo Tribunal Federal), com base no Informativo n 975 do referido Tribunal, a partir do qual elaborou-se a síntese abaixo:

1) Direito Constitucional - Seguridade Social - COVID-19: Ação Direta de Inconstitucionalidade por Omissão (ADO) e fixação de renda temporária mínima (ADO $n^{\circ}$ 56/DF, relator Ministro Marco Aurélio, redator para o acórdão Ministro Roberto Barroso, julgamento em 30 de abril de 2020).

Inobstante o pedido de fixação de renda temporária mínima para fazer frente à pandemia, o plenário, por maioria, julgou prejudicado tal pedido formulado em Ação Direta de Inconstitucionalidade por Omissão, uma vez que foi aprovado, pelo Congresso Nacional, o auxílio emergencial e, consequentemente, satisfeito o que seria o objeto do pedido. Vencido, nesse aspecto, o ministro Edson Fachin, que deu prosseguimento à ação. Para o Ministro, a matéria deveria ter trânsito para se examinar se havia ou não o dever de legislar em matéria de renda básica, notadamente em períodos de grave crise econômico-social, mas não exclusivamente nesse âmbito (33).

2) Direito Constitucional - Organização do Estado - COVID-19: transporte intermunicipal e interestadual e competência (Ação Direta de Inconstitucionalidade $n^{\circ} 6343$ - Medida Cautelar-Referendo/DF, relator Ministro Marco Aurélio, julgamento em 30 de abril de 2020).

Iniciado o julgamento de referendo em medida cautelar em Ação Direta de Inconstitucionalidade, ajuizada contra dispositivos das Medidas Provisórias n 926/2020 e $n^{\circ}$ 927/2020, que alteraram a Lei n 13.979/2020 e tratam da competência para restrição de transporte intermunicipal e interestadual durante a situação de emergência provocada pela pandemia do novo coronavírus. Suspenso o julgamento por pedido de vista do Ministro Dias 


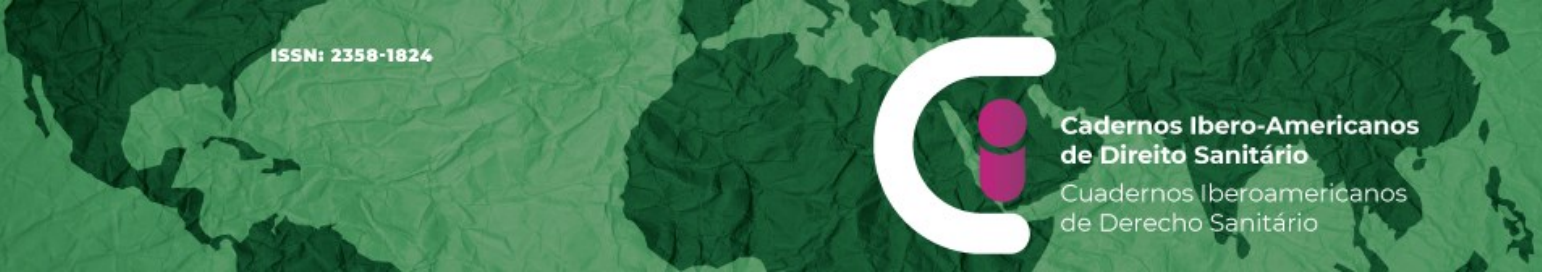

Toffoli. Destaque-se, no entanto, trechos de votos de alguns Ministros na ocasião Alexandre de Moraes, seguido pelos ministros Luiz Fux, Cármen Lúcia, Ricardo Lewandowski e Gilmar Mendes -, deferindo parcialmente a medida acauteladora, para, sem redução de texto, suspender em parte a aplicabilidade do art. $3^{\circ}$, VI, b, e $\S \S 6^{\circ}$ e $7^{\circ}$, II, da Lei $n^{\circ} 13.979 / 2020$ (1) aos estados, ao DF e aos municípios (33):

[...] não é necessário excluir a possibilidade de a União determinar a eventual interdição de rodovias para garantir o abastecimento mais rápido de medicamentos, por exemplo, sob a perspectiva de um interesse nacional. Todavia, os estados também devem ter o poder de regulamentar o transporte intermunicipal para realizar barreiras sanitárias nas rodovias, por exemplo, se o interesse for regional. Dessa forma, os poderes, nos três níveis da Federação, devem se unir e se coordenar para tentar diminuir os efeitos nefastos da pandemia. (33, grifo das autoras)

3) Direito Constitucional - Organização dos Poderes - COVID-19: direito do trabalho e pandemia do novo coronavírus (Ação Direta de Inconstitucionalidade n ${ }^{\circ s} 6342,6344,6346$, 6349, 6352 e 6354 - Medida Cautelar-Referendo/DF, relator Ministro Marco Aurélio, redator para o acórdão Ministro Alexandre de Moraes e demais ações, julgamento em 29/4/20200).

O Plenário, por maioria, em conclusão de julgamento conjunto de referendo em Medida Cautelar em Ações Diretas de Inconstitucionalidade ajuizadas contra diversos artigos da Medida Provisória (MP) n 927/2020, negou referendo ao indeferimento da medida cautelar somente em relação aos arts. 29 e 31 da referida MP e suspendeu a eficácia desses artigos. A MP n 927/2020 dispõe sobre a possibilidade de celebração de acordo individual escrito, a fim de garantir a permanência do vínculo empregatício, durante o período da pandemia do novo coronavírus (COVID-19), bem como sobre diversas providências a serem tomadas nesse período de calamidade pública, relativas aos contratos de trabalho (33).

Destaque-se que:

[...] o ministro Alexandre de Moraes afirmou que, com exceção dos arts. 29 e 31, a MP 927/2020, em seu conjunto, veio para tentar diminuir os trágicos efeitos econômicos tanto em relação ao empregado, o desemprego, a ausência de renda para sua subsistência, subsistência da sua família, quanto para o empregador, com o fechamento de inúmeras empresas e, consequentemente, com uma crise econômica gigantesca. Ou seja, veio para tentar conciliar durante esse período de pandemia. Por isso, essas medidas emergenciais não seriam inconstitucionais, porque realmente pretendem compatibilizar - e vêm atingindo em certo ponto esse objetivo - os valores sociais do trabalho. Elas perpetuam o vínculo trabalhista, após, inclusive, o término do isolamento com a livre iniciativa, e, nesse sentido, mantêm, mesmo que abalada, a saúde financeira de milhares de empresas, principalmente as micro, pequenas e médias empresas do 
setor de serviços, que geram milhões de empregos. A ideia da medida provisória na manutenção desse equilíbrio é garantir a subsistência digna do trabalhador e sua família, que continuará, dentro desses parâmetros, mantendo o seu vínculo trabalhista. (33, grifo das autoras)

Percebe-se nas decisões acima citadas, ainda que sob reduzida amostragem, que o princípio da solidariedade vem exercendo influência sobre as questões judicializadas durante o período de pandemia e o Judiciário mostrando-se sensível, dentro de um ideal colaborativo e solidário, no sentido de minimizar os efeitos trágicos da pandemia, que atingem, principalmente, os mais pobres.

\section{Outros organismos nacionais - pactos de solidariedade}

Ainda como expressão do princípio da solidariedade, organizações de caráter nãogovernamental uniram-se em torno da defesa da união da sociedade brasileira, seus cidadãos e poderes da República, no sentido de uma ampla aliança de enfrentamento da pandemia e suas consequências.

Assim, numa iniciativa conjunta entre a Conferência Nacional dos Bispos do Brasil (CNBB), a Ordem dos Advogados do Brasil (OAB), a Comissão de Defesa dos Direitos Humanos Dom Paulo Evaristo Arns (Comissão Arns), a Academia Brasileira de Ciências $(A B C)$, a Associação Brasileira de Imprensa (ABI) e a Sociedade Brasileira para o Progresso da Ciência (SBPC), foi lançado em 7 de abril de 2020, Dia Mundial da Saúde, o Pacto Pela Vida e Pelo Brasil, com o chamamento a toda a sociedade brasileira, cidadãos, governos e poderes da República, a formarem uma ampla aliança para enfrentar a grave crise sanitária, econômica, social e política que vive o país (34).

O pacto, inicialmente lançado no Brasil, já foi subscrito por mais de 100 organizações de diferentes áreas de atuação em todo o mundo.

Como anunciado pela CNBB:

[...] o documento reconhece que o Brasil vive uma grave crise - sanitária, econômica, social e política - e que exige de todos, especialmente de governantes e representantes do povo, o exercício de uma cidadania guiada pelos princípios da solidariedade e da dignidade humana, assentada no diálogo maduro, corresponsável, na busca de soluções conjuntas para o bem comum, particularmente dos mais pobres e vulneráveis. (34)

Ainda no texto do Pacto, conclamam as organizações, dentre as quais a Associação Brasileira de Ciências (ABC), que: 
[...] é imperioso que a condução da coisa pública seja pautada pela mais absoluta transparência, apoiada na melhor ciência e condicionada pelos princípios fundamentais da dignidade da pessoa humana e da proteção da vida. Reconhecemos que a saúde das pessoas e a capacidade produtiva do país são fundamentais para o bem-estar de todos. Mas propugnamos, uma vez mais, a primazia do trabalho sobre o capital, do humano sobre o financeiro, da solidariedade sobre a competição [...]. (35)

Observa-se que a sociedade civil tem se organizado para exigir dos governantes maior seriedade e responsabilidade no enfrentamento da COVID-19, com respeito aos princípios da solidariedade e da dignidade humana.

\section{A solidariedade em âmbito internacional}

Atuação decisiva da OMS

A Organização Mundial da Saúde (OMS), dentro dos seus fundamentos e princípios básicos, tem atuação pautada na solidariedade, em defesa da saúde de todos os povos, política que desenvolve mundialmente através de seus escritórios regionais.

No caso das Américas, tem-se a Organização Pan-Americana da Saúde (OPAS), que atua como escritório regional da OMS e que direciona as ações segundo as especificidades do continente americano, em observância aos aspectos culturais, econômicos e políticos de cada localidade ou país.

Em relação ao Brasil, particularmente, têm sido lançadas diretrizes de proteção, a exemplo das políticas voltadas às pessoas com maior risco de desenvolverem a forma mais grave da COVID-19, pelas suas comorbidades, bem como à população indígena, dada a condição de vulnerabilidade que apresentam.

A OPAS alerta que as complicações mais graves da COVID-19 ocorrem justamente em países onde as condições de saúde pré-existentes não são boas, como no caso das Américas, tornando nossa região mais vulnerável, e demanda a adoção de estratégias para proteger pessoas com comorbidades (36). Trata-se de doenças crônicas pré-existentes, como diabetes, doença renal, hipertensão, doenças infecciosas como a tuberculose e imunossupressoras, que colocam as pessoas em maior risco de desenvolver a forma grave da doença (36).

Para tanto, a OPAS (36) propõe, em parceria com a Escola de Higiene e Medicina Tropical de Londres, "[...] um novo modelo de dados que fornece uma imagem mais precisa da prevalência das condições de saúde nas Américas", o que ajudará países com dados 


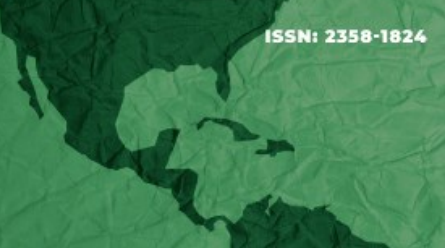

específicos a "[...] adaptar suas respostas à COVID-19 e proteger melhor as populações vulneráveis de doenças crônicas que ameaçam a saúde".

Trata-se de estratégias para proteger essas pessoas mais vulneráveis, variando do isolamento voluntário com assistência ao fornecimento de recursos e sistemas de apoio adequados, o que poderá "[...] ajudar os países a reduzir as mortes entre grupos vulneráveis, achatar a curva e preservar capacidade dos serviços de saúde" (36).

Segundo a diretora da OPAS, Carissa F. Etienne:

Com o aumento de pacientes com COVID-19, muitos sistemas de saúde carecem de pessoal, espaço e suprimentos para fornecer cuidados de rotina de forma adequada. Essas mudanças atrasaram o tratamento para pacientes com câncer e diálise para aqueles com doença renal crônica. As pessoas com diabetes estão ficando sem insulina e os pacientes com HIV precisam se preocupar em continuar seu tratamento. (36)

A ferramenta abrange a implementação de programas inovadores para ajudar as pessoas com maior risco, para que gerenciem suas condições com segurança e consistência. "Isso inclui o aumento das capacidades de telemedicina e o estabelecimento de novos pontos de apoio para atendimento, permitindo que pessoas com doenças crônicas sejam atendidas por profissionais de saúde longe de pacientes com suspeita de COVID-19" (36). Também em relação aos povos indígenas, a preocupação persiste, devendo adotar-se medidas mais eficazes de combate e proteção, o que igualmente deve abranger a implementação de ações governamentais coesas e unificadas, em solidariedade a esses povos (37).

A OPAS informou haver instado as autoridades de saúde a "[...] redobrar esforços para impedir a propagação da infecção nessas comunidades, bem como garantir o acesso aos serviços de saúde" (37). O alerta da OPAS pede o fortalecimento do manejo de casos, com abordagens culturalmente apropriadas e a implementação de medidas preventivas em todos os níveis do sistema de saúde, de modo a reduzir a mortalidade pela COVID-19.

Destaca-se, ainda, outro grande projeto integrado pela OMS, o COVID-19 Law Lab3, que reúne e compartilha documentos legais de mais de 190 países em todo o mundo, com o objetivo de "[...] garantir que as leis protejam a saúde e o bem-estar de indivíduos e comunidades e que cumpram os padrões internacionais de direitos humanos" (38). O banco de dados de leis implementadas pelos países em combate à pandemia é continuamente

\footnotetext{
${ }^{3}$ www.COVIDLawLab.org
} 
alimentado à medida que mais países e temas forem adicionados. Tal banco inclui "[...] declarações de estado de emergência, medidas de quarentena, vigilância de doenças, medidas legais relacionadas ao uso de máscaras, distanciamento social e acesso a medicamentos e vacinas", bem como pesquisas sobre diferentes marcos legais para a COVID-19, que poderão ajudar os países a "[...] identificar as melhores práticas para orientar suas respostas imediatas aos esforços da COVID-19 e de recuperação socioeconômica quando a pandemia estiver sob controle" (38).

O novo laboratório é um projeto conjunto do Programa das Nações Unidas para o Desenvolvimento (PNUD), da Organização Mundial da Saúde (OMS), do Programa Conjunto das Nações Unidas sobre HIVIAIDS (UNAIDS) e do Instituto O'Neill e Direito Nacional e Global de Saúde, ligado à Universidade de Georgetown (38).

É possível perceber a clara a atuação da OMS na defesa permanente da saúde de todos os povos, o que bem expressa a aplicação do princípio da solidariedade.

\section{Experiências estrangeiras exitosas}

Países com maior êxito no combate à COVID-19 foram exatamente aqueles que não negaram a seriedade da doença, nem tampouco o poder de sua propagação desde o início da pandemia, adotando rapidamente as medidas de isolamento social como fator determinante para a diminuição do contágio.

Mas um dado curioso foi constatado dentre os países de sucesso no combate. Em pelo menos seis deles há líderes que se assemelharam em suas ações: Islândia, sob a liderança da primeira-ministra Katrín Jakobsdóttir); Nova Zelândia, da primeira-ministra Jacinda Ardern); Taiwan, da presidente Tsai Ing-wen); Finlândia, da primeira-ministra Sanna Marin); Noruega, da primeira-ministra Erna Solberg); e Alemanha, da Angela Merkel (39).

Desde o início da pandemia, essas lideranças mantiveram discursos claros sobre a gravidade da doença e não menosprezaram as orientações da OMS, pedindo aos seus países que se unissem em torno da causa. Tal discurso aberto e transparente conquistou a opinião pública e naturalmente revelou o espírito solidário e colaborativo dessas líderes de destaque (39).

Também obtiveram sucesso nas ações de combate à COVID-19 outros líderes que adotaram postura semelhante (clareza de discurso e observância das orientações sanitárias), a exemplo do presidente Moon Jae-in, da Coreia do Sul, que assegurou a vitória esmagadora de seu partido nas últimas eleições de abril/2020, assim como o primeiro- 
ministro da Grécia, Kyriakos Mitsotakis, que gerenciou muito bem a crise e manteve as taxas de mortalidade relativamente baixas - 114 óbitos até 20 de abril, para uma população de cerca de 11 milhões. A Grécia, igualmente, priorizou o aconselhamento científico e adotou medidas precoces de distanciamento social, antes das primeiras mortes (39).

O Uruguai, além das já citadas Nova Zelândia e Coreia do Sul, foi considerado exemplo de gestão pública no enfrentamento ao coronavírus (40). Sob a presidência de Luis Lacalle Pou, o sucesso no combate ao vírus começou antes da pandemia. Em fevereiro, quando os casos começavam a crescer pelo mundo, o Ministério da Saúde Pública do Uruguai já tinha um plano de contingência (404). O país tem um dos melhores sistemas de saúde da América Latina e Caribe, e um estudo do Banco Interamericano de Desenvolvimento (BID) coloca o Uruguai em quarto lugar quando o assunto é eficiência de gastos com saúde, sendo que o sistema também é o quarto maior em investimento na região (40).

Semanas após os primeiros casos no Uruguai, foram fechados teatros, museus e shoppings. Depois, houve a suspensão das aulas, apoiadas pelo Plan Ceibal, de 2007 programa que, entre outras medidas, estabelece a entrega de laptops para alunos da rede pública. As ações rápidas do governo uruguaio, unidas a políticas já existentes de saúde e educação, permitiram que as autoridades locais flexibilizassem as regras para abertura do comércio. O resultado disso foi uma adesão voluntária ao isolamento (40).

Com isolamento rigoroso, a Nova Zelândia proibiu reuniões com mais de 500 pessoas a partir de 16 de março e fez alto financiamento para serviços de saúde no combate à doença. Em 19 de março, proibiu aglomerações de mais de 100 pessoas, exceto para locais de trabalho, escolas, transporte público e supermercados. Em 25 de março, com 205 contaminados, fechou escolas, calçadões à beira-mar e estabelecimentos comerciais (40).

Já a Coreia do Sul, destacou-se no combate por testar rapidamente a população em massa e, mesmo sem sintomas, desde janeiro. O país passou a produzir seus próprios kits de testes, chegando até a exportar o produto (40).

Como bem se vê, as experiências exitosas de outros países foram marcadas pela clareza nas informações acerca da doença e observância das medidas recomendadas pela OMS, bem como pelo espírito colaborativo e solidário de suas lideranças, o que acabou reverberando positivamente entre os próprios liderados, gerando assim uma corrente solidária de forças no combate à doença. 


\section{Considerações finais}

O estudo do princípio da solidariedade, voltado ao combate da COVID-19, trouxe maior clareza acerca de sua relevância para as ações efetivas contra a pandemia, no Brasil e no mundo, em seus mais diversos âmbitos: sanitário, político ou econômico.

Diferentemente do estigma que possa ainda remanescer, a solidariedade não deve mais ser encarada como simples ato de caridade, ligado unicamente a um ideal cristão ou filosófico, mas sim, como norte inspirador de políticas públicas e das ações dos demais poderes, para que voltem seu olhar ao bem-estar coletivo, longe de quaisquer outras divergências, de modo a conjugarem esforços na superação da crise pandêmica e suas inúmeras implicações.

Por outro lado, muito embora constitucionalmente prevista como objetivo fundamental, conforme art. $3^{\circ}$ da CRFB, a solidariedade ainda carece de uma percepção ou nível de conscientização maior acerca dos seus benefícios, enquanto valor moral, ético e jurídico, seja pelos indivíduos em si, seja pelos órgãos do Executivo e demais poderes.

Identificar políticas públicas e outras ações exitosas de enfrentamento à nova doença, sobretudo no plano internacional, reforçou também a certeza de que a solidariedade, dentro de sua matriz principiológica universal, salva vidas e se tornará sempre um instrumento menos oneroso e eficaz, com resultados que fazem diferença em tempos de crise pandêmica, quando soluções imediatas se mostram inadiáveis.

Atuar à luz do princípio da solidariedade significa adotar-se importante vetor interpretativo para a convergência das políticas públicas e demais ações de combate à crise pandêmica no Brasil, em defesa da vida humana.

\section{Referências}

1. Alexy R. Teoria dos direitos fundamentais. Tradução: Virgílio Afonso da Silva. São Paulo: Malheiros; 2008.

2. Cardoso AS. Princípio da solidariedade: o paradigma ético do direito contemporâneo. São Paulo: Editora Nova; 2013.

3. Farias JFC. A origem do direito de solidariedade. Rio de Janeiro: Renovar; 1998.

4. Beckenkamp CR, Friedrich RW. A efetivação do princípio da solidariedade como objetivo fundamental da Constituição da República do Brasil. In: Anais do XIV Seminário Nacional Demandas Sociais e Políticas Públicas na Sociedade Contemporânea [Internet]; 24-25 maio 2018; Santa Cruz do Sul (RS). Santa Cruz do Sul (RS): Universidade de Santa Cruz 


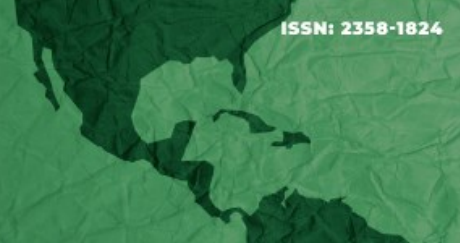

do Sul; 2018 [citado em 20 jul. 2020]; [18 p.]. Disponível em:

https://online.unisc.br/acadnet/anais/index.php/snpp/article/view/17980/1192611949

5. Quintana JG, Reis JR. O princípio da solidariedade como meio de realização do macro princípio da dignidade. Revista Digital Constituição e Garantia de Direitos [Internet]. 2018 jan. [citado em 22 jul. 2020];10(1):223-242. Disponível em:

https://periodicos.ufrn.br/constituicaoegarantiadedireitos/article/view/13470

6. Cardoso AS. Princípio da solidariedade: a confirmação de um novo paradigma. Revista Direito Mackenzie [internet]. 2012 jul. [citado em 22 jul. 2020];6(1):10-29. Disponível em: http://editorarevistas.mackenzie.br/index.php/rmd/article/view/5793

7. Cardoso AS. Princípio da Solidariedade: o paradigma ético do direito contemporâneo. São Paulo: Editora Juarez de Oliveira; 2010.

8. Reis JR, Konrad LR. O direito fundamental à solidariedade: a aplicação do instituto no direito civil. Revista Novos Estudos Jurídicos - Eletrônica [Internet]. 2015 jan./abr. [citado em 22 jul. 2020];20(1):59-87. Disponível em:

https://siaiap32.univali.br/seer/index.php/nej/article/view/7195

9.Fonseca RS. Direitos de fraternidade na teoria das gerações de direitos fundamentais. Revista do Tribunal Regional Federal da $1^{\text {a }}$ Região [Internet]. Mar. 2019 [citado em 25 jul. 2020];31(1):122-131. Disponível em: https://revista.trf1.jus.br/trf1/article/view/29

10. Perrenoud P. As competências a serviço da solidariedade [Internet]. Pátio, Université de Genève. 2003 [citado em 20 jul. 2020];25:19-24. Disponível em:

https://www.unige.ch/fapse/SSE/teachers/perrenoud/php_main/php_2003/2003_07.html

11.Brandt F, Reis JR. Princípio da solidariedade na Constituição Federal Brasileira de 1988: uma nova perspectiva social. In: Anais do III Mostra de Pesquisa de Direito Civil Constitucionalizado [Internet]; Universidade de Santa Cruz do Sul; Santa Cruz do Sul - RS; 2016 [citado em 20 jul. 2020]. Disponível em:

https://online.unisc.br/acadnet/anais/index.php/ecc/article/view/16159/4057

12.Brasil. Constituição (1988). Constituição da República Federativa do Brasil [Internet]. Brasília, DF, Senado Federal; 1988 [citado em 23 jun. 2020]. Disponível em: https://www.senado.leg.br/atividade/const/con1988/CON1988_05.10.1988/CON1988.pdf

13.Sarlet IW. A eficácia dos direitos fundamentais: uma teoria geral dos direitos fundamentais na perspectiva constitucional. 11. ed. Porto Alegre: Livraria do Advogado; 2012.

14.Moraes MCB. O princípio da solidariedade. In: Matos $\mathrm{ACH}$. (Org.). A construção dos novos direitos. Porto Alegre: Núria Fabris; 2008.

15.Casalli GM. O Princípio da Solidariedade e o artigo $3^{\circ}$ da Constituição da República Federativa do Brasil. Revista Eletrônica Direito e Política [Internet]. 2006 [citado em 24 jul. 2020];1(1). Disponível em: 


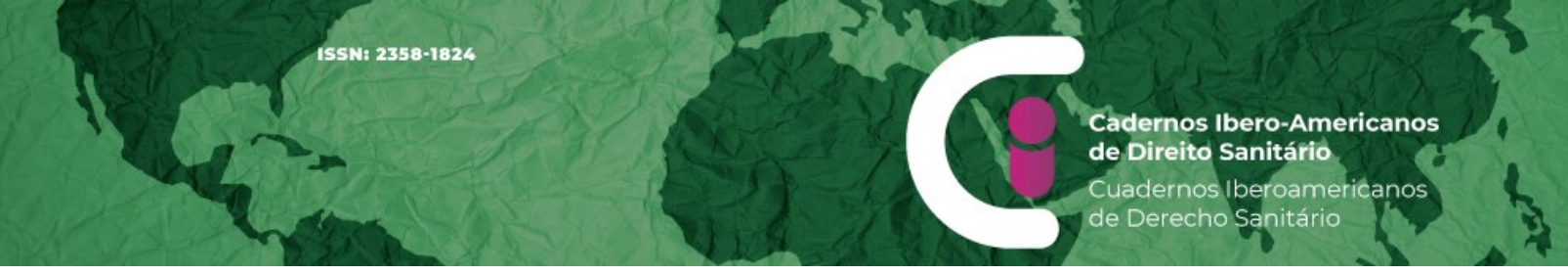

25.Brasil. Lei $n^{\circ} 8.080$, de 19 de setembro de 1990 [Internet]. Dispõe sobre as condições para a promoção, proteção e recuperação da saúde, a organização e o funcionamento dos serviços correspondentes e dá outras providências. [citado em 17 out. 2020]. Disponível em: http://www.planalto.gov.br/ccivil_03/leis//8080.htm

26. Reis DO, Araújo EC, Cecílio LCO. Políticas Públicas de Saúde no Brasil: SUS e pactos pela Saúde [Internet]. Módulo Político Gestor. [citado em 17 out. 2020]. Disponível em: https://www.unasus.unifesp.br/biblioteca_virtual/esf/1/modulo_politico_gestor/Unidade_4.pd f

27.Carli P, Naundorf B. A aplicação do princípio da solidariedade na judicialização da saúde a partir dos princípios do SUS, da fixação de entendimento pelo STF e da trajetória do Rio Grande do Sul. Cad. Ibero-amer. Dir. Sanit. [Internet]. 2019 jul./set. [citado em 17 out. 2020];8(3):112-30. Disponível em:

https://www.cadernos.prodisa.fiocruz.br/index.php/cadernos/article/view/549/610

28.Brasil. Lei $n^{0} 13.979$, de 6 de fevereiro de 2020 [Internet]. Dispõe sobre as medidas para enfrentamento da emergência de saúde pública de importância internacional decorrente do coronavírus responsável pelo surto de 2019. [citado em 18 out. 2020]. Disponível em: http://www.planalto.gov.br/ccivil_03/_ato2019-2022/2020/lei//13979.htm

29.Brasil. Supremo Tribunal Federal. Requisições de bens e serviços contra pandemia não dependem de autorização do Ministério da Saúde [Internet]. Notícias STF; set. 2020 [citado em 18 out. 2020]. Disponível em:

http://www.stf.jus.br/portal/cms/verNoticiaDetalhe.asp?idConteudo=450880

30.Marrafon MA. Constituição e poder: CF estabelece cooperação federativa para superar crise do coronavírus. Revista Consultor Jurídico [Internet]. Mar. 2020 [citado em 20 jul. 2020]. Disponível em: https://www.conjur.com.br/2020-mar-30/constituicao-poder-cfestabelece-cooperacao-federativa-crise-covid-19

31.UOL. Por prazo de validade, governo pode jogar fora milhões de testes [Internet]. Nov. 2020 [citado em 28 nov. 2020]. Disponível em:

https://www.bol.uol.com.br/noticias/2020/11/22/jornal-por-prazo-de-validade-governo-podejogar-fora-milhoes-de-testes.htm

32.Sassine V. Governo não gasta verba da pandemia para profissionais de saúde, hospitais e alimentos. Folha de São Paulo [Internet]. Nov. 2020 [citado em 28 nov. 2020]. Disponível em: https://www1.folha.uol.com.br/equilibrioesaude/2020/11/governo-nao-gastaverba-da-pandemia-para-profissionais-de-saude-hospitais-e-alimentos.shtml

33.Brasil. Supremo Tribunal Federal. Informativo STF № 975. Brasília, DF; 2020 [citado em 20 jul. 2020]. Disponível em:

http://www.stf.jus.br/arquivo/informativo/documento/informativo975.htm

34. Conferência Nacional dos Bispos do Brasil (CNBB). CNBB une-se a cinco organizações da sociedade civil e assina pacto pela vida e pelo Brasil [Internet]. 2020 [citado em 23 jul. 2020]. Disponível em: https://www.cnbb.org.br/no-dia-mundial-da-saude-cnbb-assinapacto-pela-vida-e-pelo-brasil/ 
